Article History: Received: 1 March 2020; Revised: 18 May 2020; Accepted: 6 June 2020

Book Review

\title{
Book Review: The Politics of Language Contact in the Himalaya
}

\section{The Politics of Language Contact in the Himalaya}

Selma K. Sonntag \& Mark Turin (Eds.), 2019

Cambridge, England: Open Book Publishers

200 pp., ISBN $9781783747047, £ 17.95$ (Paperback)

https://doi.org/10.11647/OBP.0169

Reviewed by Tikaram Poudel* Kathmandu University School of Education, Lalitpur, Nepal

The arguments of The Politics of Language Contact in the Himalaya are grounded in the multidisciplinary nature of area studies i.e., linguistics, political science, anthropology and geography. Focusing on the area study of the trans-border region of the Himalaya, the contributors enrich their arguments through specific case studies of their respective areas. For all the contributors, the issues of language contact are central and all of them provide contextual analyses of this issue. The contributors raise placing their issues in the emerging discourse of language contact making the collection accessible not only to linguists but also to scholars interested in anthropology, sociolinguistics, political science and Asian studies.

This is a collection of five contributions from a wide range of expertise and the editors, Selma K. Sonntag and Mark Turin, of the volume supplement with an introduction and a section on concluding thoughts respectively. Introducing the main

* Reviewer Email: tikaram.poudel@ kusoed.edu.np

https://orcid.org/0000-0002-6963-7013

ISSN: 2091-0118 (Print) / 2091-2560 (Online)

Journal homepages: ${ }^{1}$ http://www.kusoed.edu.np/journal/index.php/je

${ }^{2}$ https://www.nepjol.info/index.php/JER/index

(i) (2) Published by Kathmandu University School of Education, Lalitpur, Nepal.

This open access article is distributed under a Creative Commons Attribution (CC BY-SA 4.0) license. 


\section{$120 \mid$ T. Poudel}

thrust of the volume, Sonntag, one of the editors of the collection, disambiguates the term 'language politics'. For her the term 'language politics' refers to 'language of politics' and 'politics of language' and she claims the 'politics of language' is the underlying theme of the contributions here. The discourse of 'politics of language' got dominance in the Post World War II decolonization period through the ideology of monolingualism, however, this ideology was challenged under post-structural approaches replacing this ideology with the ideology of multilingualism informed by the political theories.

The contribution of Tunzhi (Sonam Lhundrop), Hiroyuki Suzuki, and Gerald Roche on 'Language Contact and the Politics of Recognition amongst Tibetans in the People's Republic of China: The rTa'u-Speaking 'Horpa' of Khams' discuss the language contact situation of the rTa'u-speaking 'Horpa' of Khams within the theoretical framework of 'recognition'. The linguistic hierarchy between the rTa'u language and dominating Tibetan, the authors argue, leads to social exclusion, economic marginalization, personal discrimination and other forms of oppression to the speakers of the rTa'u language. Since language hierarchy represents 'collective recognition' not 'personal recognition' of the rTa'u speakers, they construct the collective identity of the inferiority of the entire community. In the context of the speakers of the rTa'u language, the written Tibetan constructs regional linguistic hierarchies in relation to the Tibetans because of the misconception of the idea that Tibet is a linguistically homogenous entity. They also suffer another linguistic hierarchy at the national level because of the language of mainland China, i.e., Standard Chinese, leading to further social exclusion and economic marginalization at the national level.

Taking the case of the rTa'u language, these authors argue that the state misrecognised the speakers of the rTa'u language as the state has categorised them as Tibetans. However, the rTa'u language is different from Tibetan though it has borrowed a large number of lexicons from Tibetan in its long historical contact with Tibetan. Such a misrecognition, not only led to the social exclusion and economic marginalization but also the younger generation of the rTa'u community shifted to dominating Tibetan leading the severe endangerment of the rTa'u language.

The social exclusion and economic marginalization of the rTa'u speakers, as the authors argue, is the manifestation of the monolingual and standard language ideology 
of the state. Such ideologies put the minority languages like rTa'u in the lowest layer of hierarchy with labels such as 'corrupt', 'non-standard' and so on. Strategic programs of state informed with the ideology of monoglot contributes to the construction of a different identity of the rTa'u speakers undermining the perceived values of indigenous communities like the rTa'u speakers. The contribution concludes that the hegemonic position of monoglot language ideologies demonstrates the destiny of the rTa'u community concerning contemporary visions of Tibetanness.

To understand the language politics in the Indian state of Assam, Selma K. Sonntag's chapter 'What Happened to the Ahom Language?' offers a case study of language contact situation in mediaeval Ahom kingdom, British and post-colonial India. Sonntag argues that the speakers of Ahom, a language of the Tai-Kadai family shifted to Assamese, an Indo-Aryan language. The mediaeval Ahom kingdom was a mandalastate, as opposed to the nation-state of linguistic homogeneity of 'post-Westphalia Europe' that co-existed with other Assamese speaking kingdoms. However, the shift to the Assamese started in the seventeenth century because of the rapid expansion of NeoVaishnavism eastward with its poetry and prose of the bhakti cult. In the midseventeenth century, the Ahom kingdom converted to Hinduism and neo-Vaishnavism received royal patronage by Ahom rulers to the Assamese. Ahoms were warriors and conquerors; they married local women and their siblings adopted the language of their mothers. By the time the British conquered Assam in the following century, they preferred to rule Assam from Bengal giving a lower status to the Assamese as Bangla was imposed as a language of governance and administration. After the decolonization of India in 1947, the federal states were reorganised under the State Reorganization Act of 1956 on the linguistic basis and the Assamese language became the state language of Assam.

In the third chapter of the book, Uma Pradhan takes a case study of a school in the southern plains of Nepal that implements a multi-lingual education program, a government initiative. She argues that, in the process of implementation, Tharu, an oral language has been transformed into a written one in the process of preparing it for the formal education system. The concerned textbook writers and school authorities were aware of the fact that Tharu did not have a written literary tradition. This transformation of the Tharu language to a written one brought this minority language into close contact with Nepali, the more dominant language of the education system of Nepal. This 


\section{$122 \mid$ T. Poudel}

contact upgraded this minority language to linguistic authority in the broader linguistic landscape of Nepal. This process of transformation of the Tharu language got reconfigured and standardised to the status of a language from its existing dialectal status in the local context and enabled its speakers to claim the authenticity of their language.

The developers of the Tharu curriculum, especially the writers of textbooks, were concerned with the inclusion of the local indigenous knowledge system of Tharu communities, not merely translating the texts from more dominating Nepali. Further, this process not only standardised the minority language but also upgraded from its dialectal status to the status of language suitable for the language of education.

In the chapter 'The Significance of Place in Ethnolinguistic Vitality', Maya Daurio takes the case of Kaike, an endangered Tibeto-Burman language in the remote district of Dolpa, Nepal to examine the ethnolinguistic vitality through the notion of space. The attitude of Kaike speakers towards their language has been changing over time. Unlike in the 1960s, the speakers embrace their language and cultural practices as valued and important. Kaike speakers, both in their homeland and their new settlements in urban areas, campaign for the promotion of their culture and language, though they prefer to send their children to English-medium schools in their urban settlements because they do not see the capital in their native language like in Nepali or English. Daurio argues that acquiring English and Nepali through formal education removes the current generation from traditional environmental knowledge of the Kaike community as such knowledge is acquired through direct experience and interaction with everyday cultural practices but this English educated generation had to live away from its homeland. In the context of Nepal, the linguistic and cultural erosion of minority communities is often ascribed to the Nepali language. Daurio convincingly argues that the modern education system is responsible for the linguistic and cultural erosion of the Kaike community because a large number of people move away from their homeland for higher education. Consequently, they are denied access to their linguistically transmitted knowledge of their community.

In the chapter 'Speaking Chone, Speaking 'Shallow', Bendi Tso and Mark Turin examine how the speakers of Chone variety of Tibetan, spoken in Yarru village of Chone County in Tibetan Autonomous Prefecture (TAP) of Gansu Province, suffer dual 
hegemonies of regional Amdo Tibetan and national Mandarin Chinese because of the Chinese language policy. Two components of hegemony - coercion and consent - are at work in marginalizing the speakers of Chone variety from the mainstream linguistic landscape of China. The institutional coercion implemented through language policies enabled Amdo Tibetan and Mandarin Chinese to create a language hierarchy putting Mandarin Chinese at the top, Amdo Tibetan next and Chone Tibetan at the lowest level. This hierarchy creates a different perception of minority language speakers such as Chone from dominant languages such as Amdo Tibetan and Mandarin Chinese that dominant languages are legitimate, prestigious and authentic. The popular discourses concerning the language policy of China are the promotion of Chinese in all domains of public life and the encouragement of minority languages to preserve through the process of standardization. However, the speakers of a minority language variety like Chone do not see any economic or social capital in it and they prefer to invest their time to learn Mandarin Chinese or Amdo Tibetan. Such a perception of speakers of these minority languages undervalue their heritage language and accelerate the language shift to more dominant languages such as Amdo Tibetan or Mandarin Chinese.

The book ends with Mark Turin's 'Concluding Thoughts...'. The Greater Himalayan Region that stretches from Afghanistan to the west of Myanmar is the home for over 150 million people speaking a diverse range of languages, many of them are endangered. Getting insight with the Sonntag's discussion on Ahom in the Indian state of Assam in the present volume, Turin argues that language shift is a historical process located in the past, rather than a modern-day one. A large number of these languages have been spoken for centuries but recently, with the access of technology and language awareness, many of these have been transformed into written, a process of linguistic upgradation. Political alliance, the pressure of globalization and trade brought many minority languages of this region in contact influencing each other. Despite the coercive feature of modern nation-building, many minority languages preserve their homogenous entity.

This collection establishes that the study of language contact is a multi-disciplinary pursuit and the contributors of this volume are fully aware of this wisdom unlike confining this issue within the discipline of linguistics. Drawing insights from the theoretical takes of ethnicity, hegemony and, of course from linguistics, these contributors make an attempt to understand the politics of language in the region. Like 


\section{$124 \mid$ T. Poudel}

normative scholars working on language contact, these contributors are, not only interested in linguistic binaries of written and spoken forms, pure and authentic forms of language, but also introduce theoretical concepts of language hierarchy and language vitality in the context of Himalayan area studies.

\section{To cite this article:}

Poudel, T. (2020). Book review: The politics of language contact in the Himalaya. Journal of Education and Research, 10(2), 119-124. https://doi.org/10.3126/jer.v10i2.32724 